Inter J Nav Archit Oc Engng (2011) 3:65 71

DOI 10.3744/JNAOE.2011.3.1.065

\title{
CFD as a seakeeping tool for ship design
}

\author{
Sungeun (Peter) Kim
}

ABS, Houston, Texas, USA

\begin{abstract}
Seakeeping analysis has progressed from the linear frequency-domain $2 D$ strip method to the nonlinear timedomain 3D panel method. Nevertheless, the violent free surface flows such as slamming and green water on deck are beyond the scope of traditional panel methods based on potential theory. Recently, Computational Fluid Dynamics (CFD) has become an attractive numerical tool that can effectively deal with the violent free surface flows. ABS, as a classification society, is putting forth a significant amount of effort to implement the CFD technology to the advanced strength assessment of modern commercial ships and high-speed naval craft. The main objective of this study is to validate the CFD technology as a seakeeping tool for ship design considering fully nonlinear three-dimensional slamming and green water on deck. The structural loads on a large container carrier were successfully calculated from the CFD analysis and validated with segmented model test measurements.
\end{abstract}

KEY WORDS: Nonlinear Seakeeping; CFD; Slamming; Green Water; Structural Loads; Container Carrier; Segmented Model Tests.

\section{INTRODUCTION}

As modern commercial ships continue to increase in size, capacity and speed, the hull structures are more likely to experience highly nonlinear ship motions and wave loads. For the structural integrity and safety of the large vessels, the ABS Guide for Dynamic Loading Approach for Vessels recommends nonlinear seakeeping analysis to accurately predict the nonlinear wave loads in design wave conditions (Kim et al., 2006).

Over the last few decades, seakeeping analysis has made a successful advance from the linear frequency-domain $2 \mathrm{D}$ strip method to the nonlinear time-domain 3D panel method. The computer programs LAMP and NLOAD3D are typical examples of the nonlinear time-domain 3D panel method, which have been widely used for ship design. NLOAD3D is the ABS in-house computer program for the so-called weakly nonlinear seakeeping analysis, considering nonlinear hydrostatic restoring and Froude-Krylov forces along with linear diffraction and radiation forces. Assuming that primary nonlinearity in ship motions and wave loads comes from the nonlinear hydrostatic restoring and Froude-Krylov forces, the weakly nonlinear analysis is being considered as an efficient and practical method for ship design.

NLOAD3D, coupled with a simple elastic beam model, was successfully validated for springing loads on a large

Corresponding author: Sungeun (Peter) Kim

e-mail:sungeunkim@eagle.org container carrier by comparing with segmented model tests (Kim et al. 2010) and full-scale measurements (Lee et al., 2010). Also NLOAD3D, coupled with a simplified 2D slamming model, was successfully validated for whipping loads on a large Arctic ore carrier by comparing with segmented model tests (Yu et al., 2010).

Recently, Kim et al. (2010) presented model test measurements of nonlinear structural loads on a 6500 TEU container carrier. The vertical and horizontal bending and torsion moments were measured in extreme wave conditions and compared with the weakly nonlinear panel method. In overall, the comparisons were in good agreement, but the weakly nonlinear approach seemed to be over-estimating the wave-induced component of sagging moment. This might be attributed to the fact that the nonlinear effects such as bow slamming and green water on deck cannot be fully considered in the weakly nonlinear analysis.

The main objective of this study is to carry out fully nonlinear seakeeping analysis and validate the currently available CFD technology as a seakeeping tool for ship design.

With rapid developments of computational resources and numerical schemes, CFD technology has become an attractive numerical tool that can effectively deal with the violent free surface flows. The CFD technology has been used for specific applications such as sloshing loads on LNG cargo containment system. However, the CFD applications for seakeeping analysis are still very limited thus far. Numerical simulations of nonlinear wave-body interactions were presented by $\mathrm{Hu}$ and Kashiwagi (2006) using the CIP 
method, by Yang et al. (2007) using the finite element and volume-of-fluid (VOF) method, and by Chen and Yu (2009) using the finite analytic Navier-Stokes (FANS) and the levelset method.

This study is focused on the global ship motions and structural loads considering the violent free surface flows such as three-dimensional slamming and green water on deck. The local impact loads are not addressed in this paper. The experimental or numerical analysis of the local impact loads can be a challenging task, which will require further study in the near future. All the simulations in this study were carried out using a commercial CFD program called STAR-CCM+. A high-performance cluster with 16 core processors was used fully utilizing the MPI-based parallel computing technology.

\section{CONSIDERATIONS ON CFD MODELING}

The description on the mathematical formulations and numerical schemes implemented in the CFD method is not the scope of this paper. The numerical schemes of STAR$\mathrm{CCM}+$ are presented by Ferziger and Peric (2003). In this section, specific considerations on CFD modeling for fully nonlinear seakeeping analysis are discussed.

\section{Physics Modeling}

The unsteady ship viscous flows are assumed to be governed by the Reynolds-averaged Navier-Stokes (RANS) equations. The equations for continuity, momentum and turbulence properties are generally given in integral forms and transformed into a system of algebraic equations by the discretization schemes such as finite-volume method (FVM).

A turbulence model such as eddy-viscosity model $(k-\varepsilon$ or $k$ - $\omega$ model) may be used for ship viscous flows. A specific numerical algorithm such as SIMPLE algorithm may be used for pressure calculation by solving the pressure correction equation derived from the continuity equation.

For the modeling of violent free surface flows with possible air trapping, a two-phase fluid model is to be considered. In order to effectively capture the interface between the water and air, the volume of fluid (VOF) method may be used by solving an additional equation for the volume fraction of air.

The equations of ship motion in waves are derived by considering all the inertial and hydrodynamic forces and moments acting on the rigid body. The 6-DOF equations of motions are to be solved by time integration methods such as a second-order predictor-corrector scheme. Since the surgesway-yaw motions in horizontal plane have no hydrostatic restoring mechanism, a numerical course-keeping model would be required to avoid unrealistic drift motions during the motion simulation. Otherwise, only the heavy-roll-pitch motions in vertical plane may be considered as a simplified approach. For the accurate modeling of roll damping, ship appendages like bilge keels and rudders are to be considered in the geometry modeling. Otherwise, a simplified roll damping model may be used for the roll motion simulation.
For the accurate modeling of incident waves, the $5^{\text {th }}$-order Stokes waves are recommended. The incident waves are required as an initial condition as well as an inlet boundary condition. The incident waves, given at the inlet boundary, propagate inside the computational domain. At the outlet boundary, an artificial damping beach or specific outlet boundary condition is to be considered.

The computational domain size and artificial damping beach zone is to be large enough so as not to affect the flows near the ship. During the CFD simulation, due consideration is to be paid to the numerical damping, which primarily depends on mesh size and time step. The numerical damping can be reduced by providing a fair resolution of mesh size and time step. In this study, a minimum of 40 cells per wavelength is used.

\section{Geometry Modeling and Mesh Generation}

Computational domain is to be defined around the ship with a minimum one ship length in each direction. Fig. 1 shows a typical example of the geometry modeling and computational domain for a container carrier. Only a half domain may be used for a head sea or following sea considering a symmetry condition. Otherwise, full domain is to be considered for oblique seas.

As shown in Fig. 1, fine meshes near the free surface are required to provide a good resolution of the surface waves. Furthermore, finer meshes around the ship are also required to accurately capture the violent free surface flows such as slamming and green water on deck. In this study, a minimum of 150 cells per wavelength is used to effectively account for the violent free surface flows. For the sake of seakeeping analysis, the viscous boundary layer is not necessarily resolved inside the finer meshes.

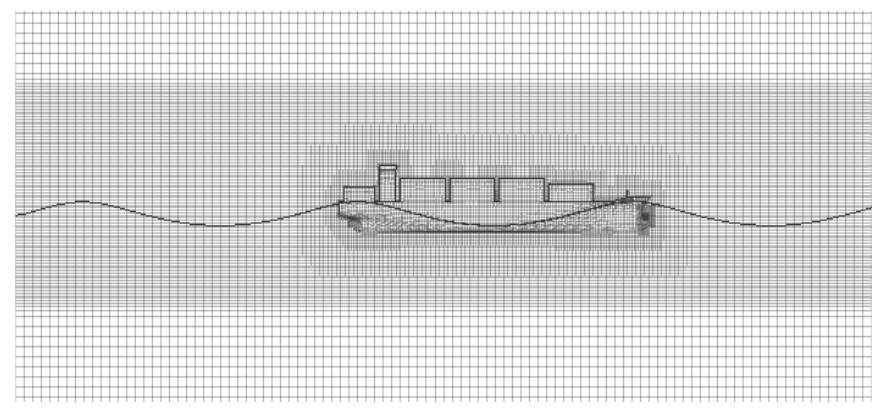

Fig. 1 Typical geometry modeling and mesh generation of a container carrier in design waves.

For the numerical simulation of green water on deck, the upper structures of the ship geometry are to be accurately modeled. Fig. 1 shows the geometry modeling of a containership including the breakwater, deckhouse and container cargos on deck.

The nonlinear motion simulation of a floating body in waves can be a challenging task because the position of the ship geometry is changing at every time step. Numerical schemes such as embedded mesh or overlapping grid may be considered for the nonlinear motion simulation. In this study, 
as a simplified approach, the entire computational mesh is moving along with the ship motions while updating the position of free surface at each time step.

\section{Structural Load Calculations}

The calculations of structural loads are required for the strength assessment of hull structures. Most CFD methods do not provide a generic capability to calculate the structural loads, which requires numerical integration of inertial and hydrodynamic loads. Fig. 2 shows the typical definition of VBM at a section $x=x_{C}$. The shear forces and bending moments may be expressed as follows:

$F_{C}=\sum_{n=1}^{N_{C}} m_{n}\left(\ddot{x}_{n}-g\right)-\iint_{S_{C}} p n d S$

$M_{C}=\sum_{n=1}^{N_{C}}\left(x_{n}-x_{C}\right) \times m_{n}\left(\ddot{x}_{n}-g\right)-\iint_{S_{C}}\left(x-x_{C}\right) \times p n d S$

where

$N_{C}$ : number of mass from $x=0$ to $x=x_{C}$

$m_{n}:$ lumped mass

$\ddot{x}_{n}$ : local acceleration at $x_{n}$

$S_{C}$ : hull surface from $x=0$ to $x=x_{C}$

$p:$ pressure on the hull surface

$n:$ normal vector of hull surface

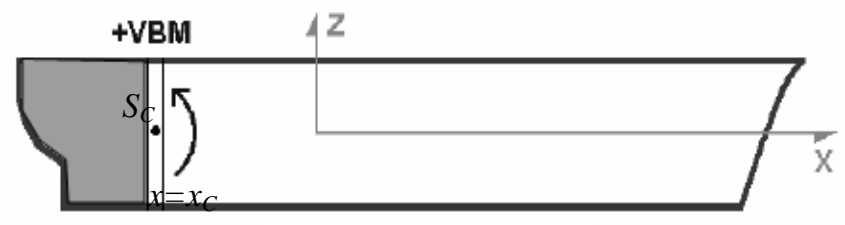

Fig. 2 Definition of vertical bending moment.

The local acceleration at $x_{n}$ is given as follows:

$\ddot{x}_{n}=\ddot{x}_{T}+\ddot{\theta} \times\left(x_{n}-x_{G}\right)$

where

$x_{T}$ : surge, sway and heave motion

$\theta:$ roll, pitch and yaw motion

$x_{G}$ : ship center of gravity

The structural load calculations are successfully carried out by the user-defined field functions and Java macro developed in this study.

\section{SEGEMENTED MODEL TESTS}

In 2006 and 2007, a joint industry project of Wave Induced Loads on Ships (WILS) conducted a series of segmented model tests to measure the nonlinear wave loads on a 6500 $T E U$ class container carrier. The model tests were carried out at the ocean wave basin of Maritime and Ocean Engineering Research Institute (MOERI) in Korea. As shown in Fig. 3, the model was equally divided into four segments. Each segment was connected by a six-component load cell, where the structural loads were measured. The principal dimensions and loading conditions are given in Table 1.

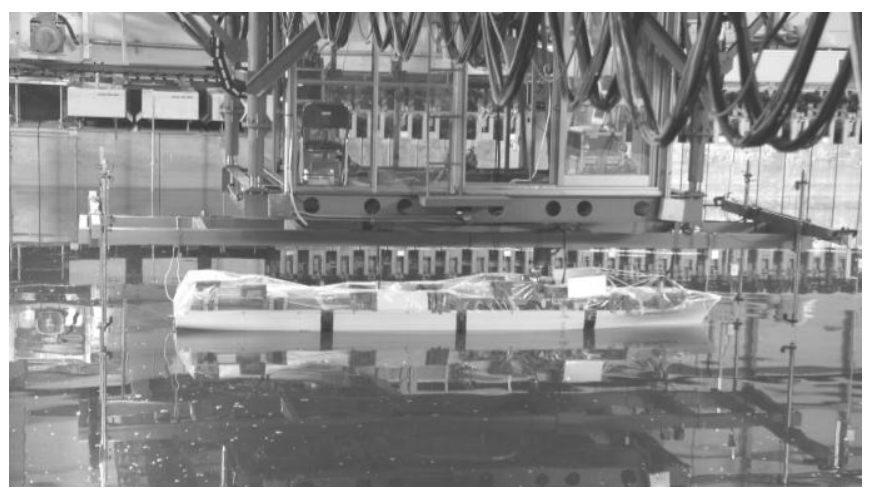

Fig. 3 Segmented model test of a container carrier at the ocean wave basin of MOERI.

Based on the analysis procedure in the ABS Guide on Dynamic Loading Approach for Vessels, equivalent design waves can be determined from the long-term spectral analysis and operational considerations for each dominant load parameter (DLP). Table 2 shows the regular wave conditions considered in the model tests.

Table 1 Principal dimensions and loading conditions.

\begin{tabular}{|c|c|}
\hline \multicolumn{2}{|c|}{ Principal } \\
\hline $\operatorname{Lpp}(m)$ & 300.250 \\
\hline $\mathrm{B}(m)$ & 40.300 \\
\hline $\mathrm{D}(m)$ & 24.100 \\
\hline $\mathrm{T}(m)$ & 14.021 \\
\hline Shear Center below BL $(m)$ & 12.050 \\
\hline \multicolumn{2}{|c|}{ Loading Condition } \\
\hline $\mathrm{TA}(m)$ & 13.127 \\
\hline $\mathrm{TF}(m)$ & 12.973 \\
\hline LCG from $\mathrm{AP}(m)$ & 136.018 \\
\hline VCG form $\mathrm{BL}(m)$ & 17.816 \\
\hline Roll Radius of Gyration $(\mathrm{m})$ & 15.881 \\
\hline Pitch Radius of Gyration $(\mathrm{m})$ & 68.880 \\
\hline Yaw Radius of Gyration $(\mathrm{m})$ & 68.552 \\
\hline
\end{tabular}

Table 2 Tested wave conditions.

\begin{tabular}{|c|c|c|c|c|c|}
\hline $\begin{array}{l}\text { Test } \\
\text { No. }\end{array}$ & DLP & Location & $\begin{array}{c}\text { Heading } \\
(\mathrm{deg})\end{array}$ & $\begin{array}{c}\text { Freq } \\
(\mathrm{rad} / \mathrm{s})\end{array}$ & $\begin{array}{c}\mathrm{H} \\
(\mathrm{m})\end{array}$ \\
\hline 141 & VBM & Mid. & 80 & 0.5 & 19.0 \\
\hline 951 & HBM & Mid. & 120 & 0.75 & 8.43 \\
\hline 641 & TM & 1/4L from AP & 60 & 0.7 & 9.66 \\
\hline 147 & TM & Mid. & 120 & 0.85 & 6.56 \\
\hline 642 & TM & 3/4L from AP & 60 & 0.75 & 8.43 \\
\hline
\end{tabular}




\section{FULLY NONLINEAR SEAKEEPING ANALYSIS}

\section{Computational Domain and Mesh Generation}

The computational domain and mesh generation for the fully nonlinear seakeeping analysis of a 6500 TEU class container carrier is given in Fig. 4. A number of total $560 \mathrm{~K}$ volume cells are used for the full domain considering the oblique wave conditions.

Also a numerical wave probe is shown in Fig. 4, located ahead of the ship. This wave probe can be used to monitor the wave elevations during the CFD simulation. For the current setting of mesh size and time step, a very small reduction of wave elevations was observed (only about $2 \%$ per wave cycle), indicating very low level of numerical damping.

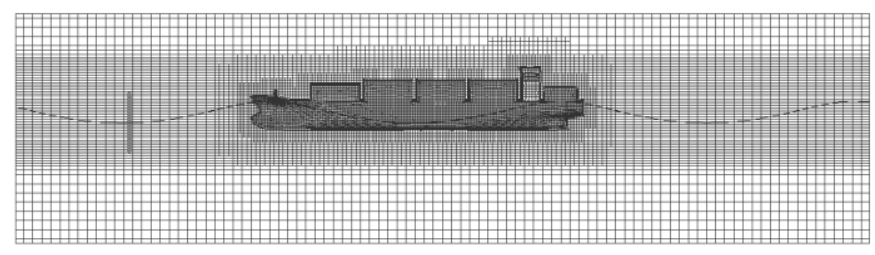

Fig. 4 Computational domain and mesh generation of the 6500 TEU container carrier.

\section{Vertical Bending Moment}

Test No. 141 in Table 2 is the wave condition that represents the lifetime maximum vertical bending moment (VBM) amidships. For this extreme wave conditions, the model test was very challenging due to the occurrence of significant slamming and green water on deck.

Fig. 5 shows the geometry modeling and mesh generation of the vessel in the regular waves of Test No. 141 at $t=0$. The ship has forward speed of 5 knots in head sea condition with a wave height of $19 \mathrm{~m}$. Fig. 6 illustrates the instantaneous snapshots of the ship at simulation time $t=6 \mathrm{sec}, 9 \mathrm{sec}, 12 \mathrm{sec}$, and $15 \mathrm{sec}$, respectively. The ship is experiencing large amplitude ship motions combined with severe bow slamming and green water on deck. There is no stern slamming observed in the head sea condition, as expected.

During the segmented model tests, vertical bending moments were directly measured at the load cells. Fig. 7 shows the time history of the measured VBM amidships (solid blue line). The high-frequency components in the measured VBM come from the transient hull-girder responses of the segmented model. However, simply connected by load cells without backbone, these transient responses may not represent the actual whipping responses of the vessel.

From a Fourier analysis, the power spectral density of the measured VBM is as shown in Fig. 8. The highest peak corresponds to the first harmonic at the wave frequency of encounter. The peaks at frequency higher than $2.5 \mathrm{rad} / \mathrm{s}$ correspond to the transient responses of the segmented model, which can be removed by a low pass filter.
Fig. 9 shows the measured VBM with low pass filter (solid blue line) and calculated VBM from the fully nonlinear CFD analysis (dashed red line). It can be seen that the fully nonlinear CFD method gives an excellent agreement with model test measurements. The weakly nonlinear panel method underestimates the hogging moment (negative) and overestimates the sagging moment (positive), ending up with a very high sag/hog ratio. For the fully nonlinear CFD method, the sag/hog ratio is significantly reduced by considering the 3D slamming and green water on deck.

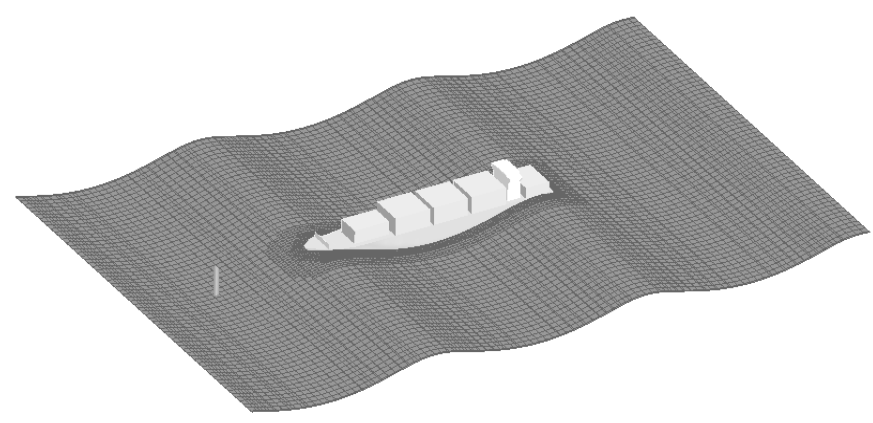

Fig. 5 Geometry modeling and mesh generation of the ship in regular waves of Test No. 141 at $t=0 s$.
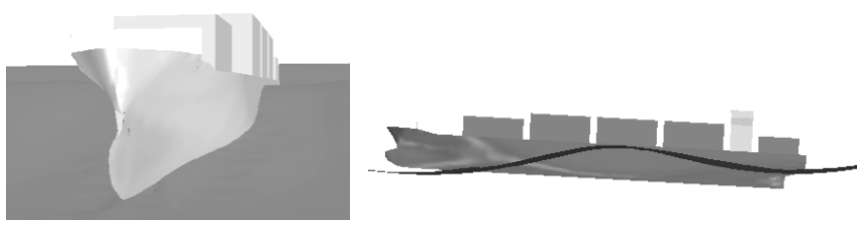

(a) $t=6 \mathrm{sec}$
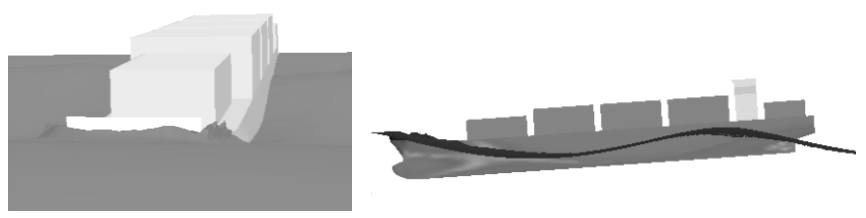

(b) $t=9 \mathrm{sec}$
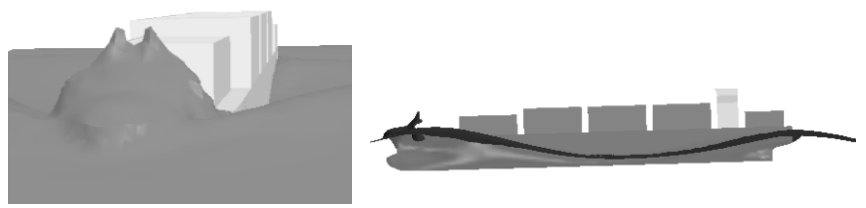

(c) $t=12 \mathrm{sec}$
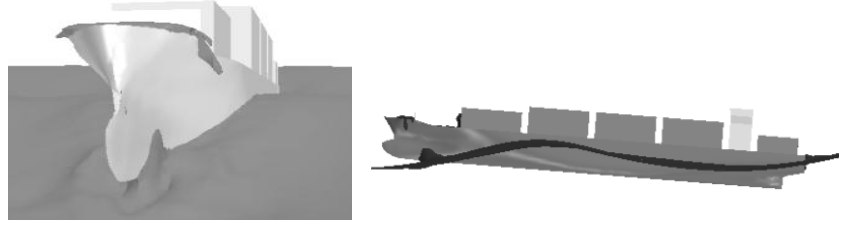

(d) $t=15 \mathrm{sec}$

Fig. 6 Instantaneous snap shots of nonlinear ship motions at each simulation time when $t=6 s, 9 s, 12 s$, and $15 s$. 


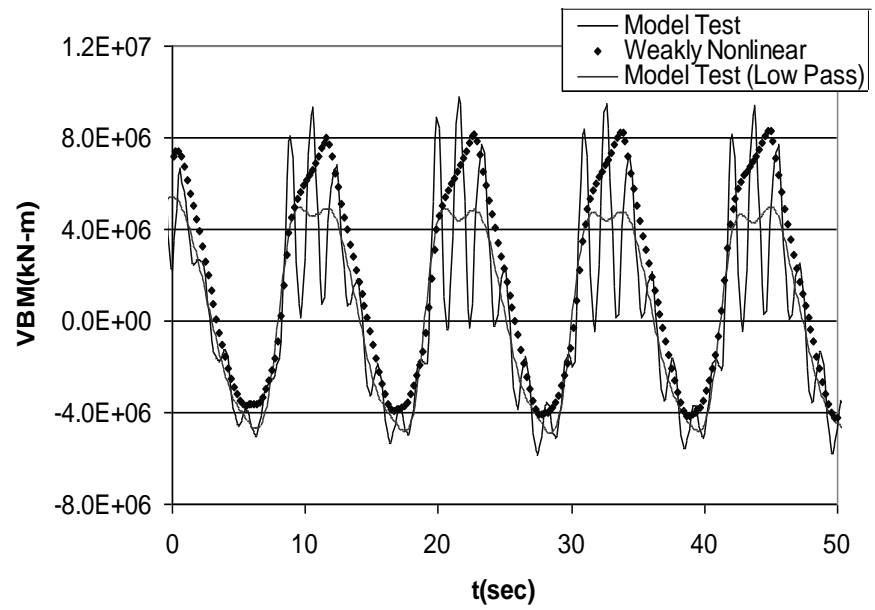

Fig. 7 Vertical bending moment amidships in the regular waves of Test No. 141.

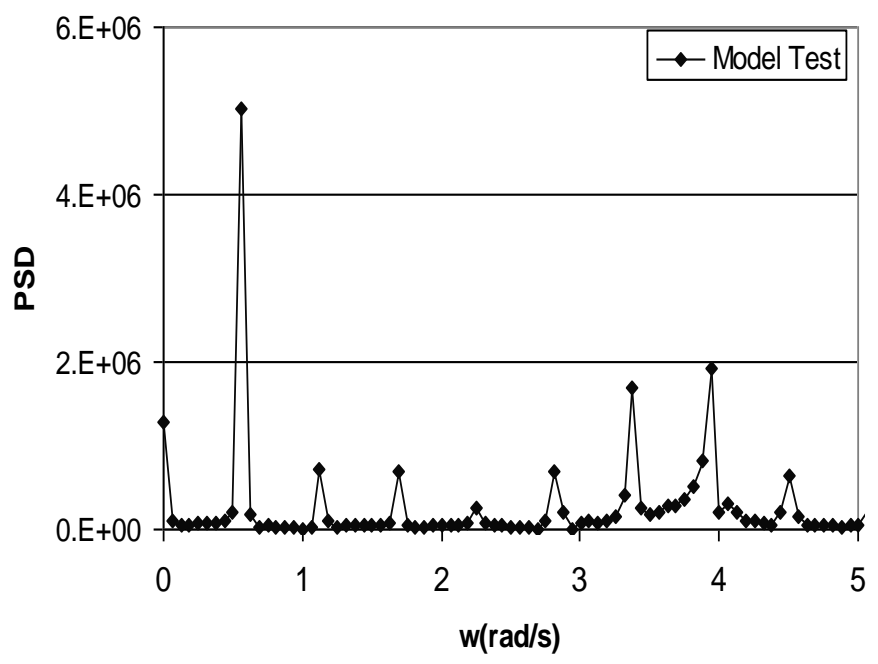

Fig. 8 Vertical bending moment amidships in the regular waves of Test No. 141.

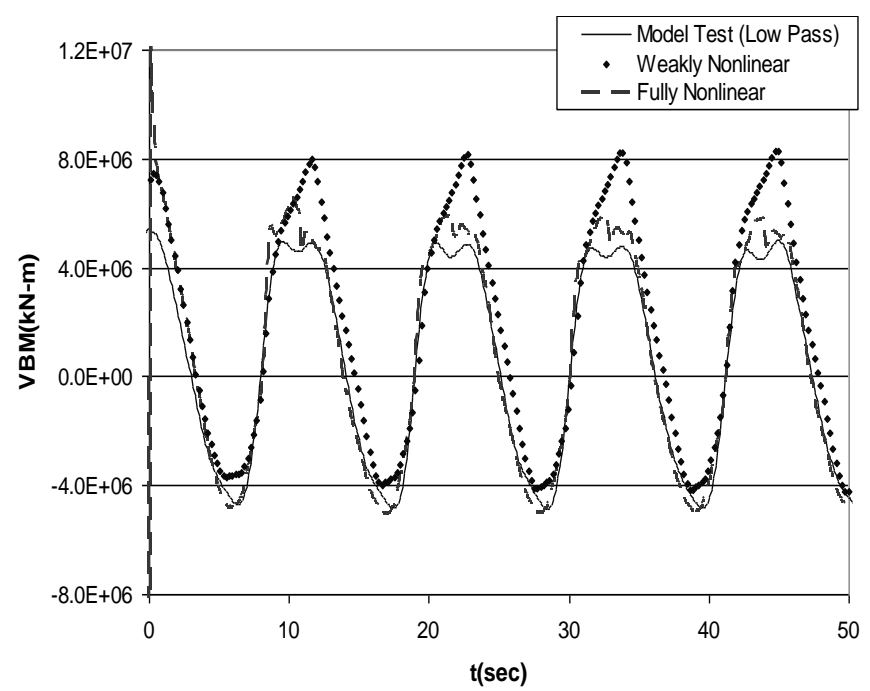

Fig. 9 Vertical bending moment amidships in the regular waves of Test No. 141.

\section{Horizontal Bending Moment}

Test No. 951 in Table 2 is the wave condition that represents the lifetime maximum horizontal bending moment (HBM) amidships.

Fig. 10 shows the geometry modeling and mesh generation of the ship in the regular waves of Test No. 951 at $t=0 s$. The ship is moving forward at 5 knots in bow quartering seas with a wave height of $8.43 \mathrm{~m}$ and wave heading of $120 \mathrm{deg}$.

Fig. 11 shows the time history of the measured and calculated HBM amidships in regular waves of Test No.951. The high-frequency components of HBM are also measured in the model test (solid line), but the magnitudes are smaller than that of VBM. The measured and calculated HBM are in good agreement. Note that the positive and negative HBM are not symmetric due to the nonlinear effects in bow quartering seas.

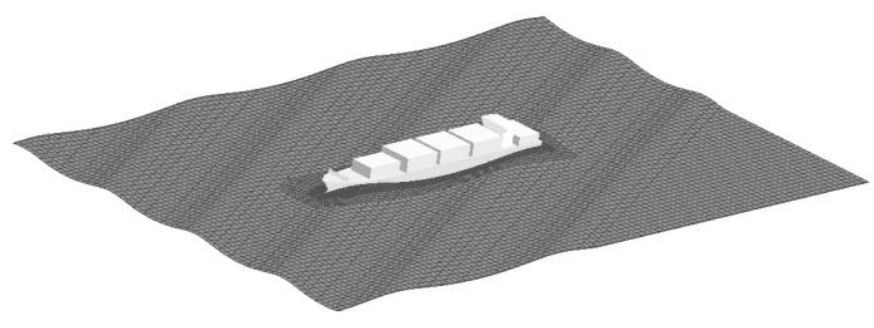

Fig. 10 Geometry modeling and mesh generation of the ship in the regular waves of Test No.951 at $t=0 s$.

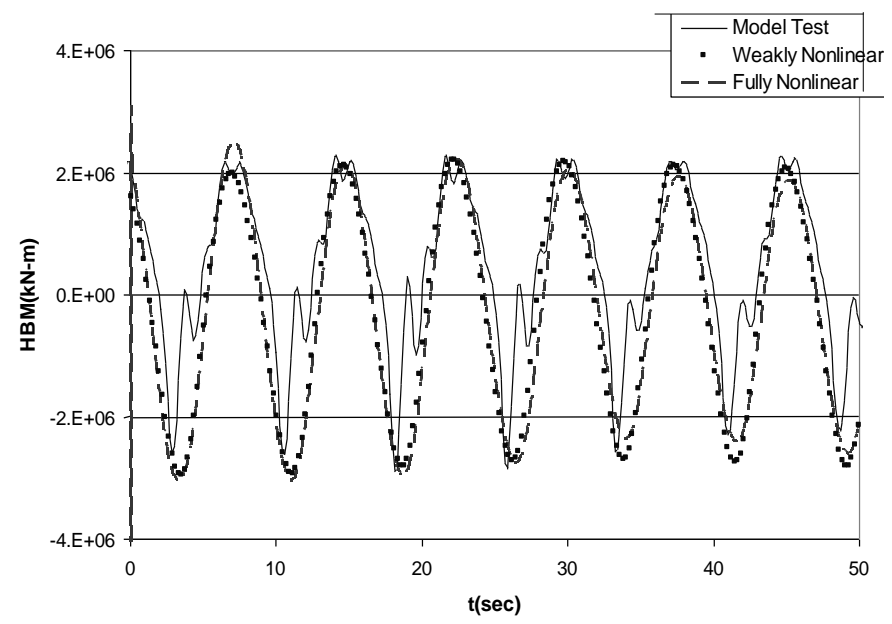

Fig. 11 Horizontal bending moment amidships in the regular waves of Test No. 951.

\section{Torsion Moment}

Test No. 641 is the wave condition that represents the lifetime maximum torsion moment (TM) at $x=L / 4$ from AP.

Fig. 12 shows the geometry modeling and mesh generation of the ship in the regular waves of Test No. 641 at $t=0$. The ship is moving forward at 5 knots in stern quartering seas with a wave height of $9.66 \mathrm{~m}$ and wave heading of $60 \mathrm{deg}$. 
Fig. 13 shows the time history of the measured and calculated torsion moment at $x=L / 4$ from AP. The measured torsion moments (solid line) are compared with the weakly nonlinear panel method and fully nonlinear CFD method (dashed line). The measured TM shows a very good agreement with the fully nonlinear CFD method. The positive and negative TM is not symmetric, as is the case of HBM. Note that the weakly nonlinear panel method is overpredicting the negative peaks.

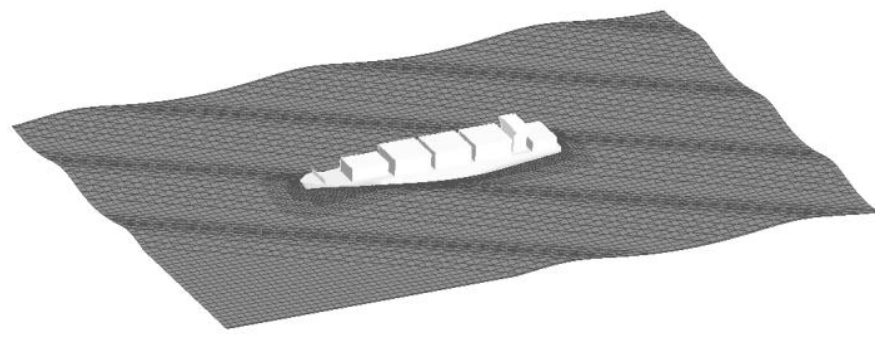

Fig. 12 Geometry modeling and mesh generation in the regular waves of Test No. 641 at $t=0$.

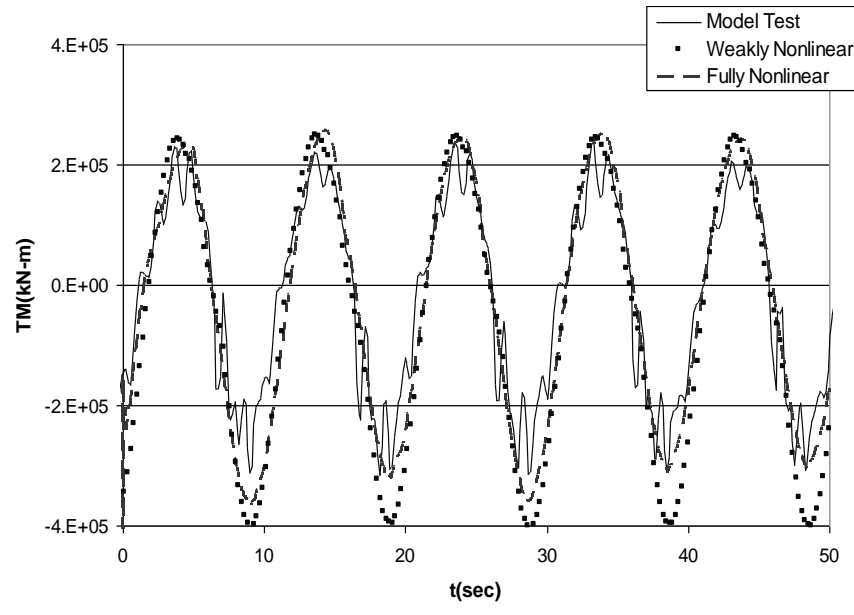

Fig. 13 Torsion moment at $x=L / 4$ from AP in the regular waves of Test No. 641.

\section{Green Water on Deck}

For the regular waves of Test No. 141, the green water on deck was successfully simulated by CFD analysis. Fig. 14 illustrates the instantaneous snapshots of the pressure distributions due to the green water on the deck and breakwater. Numerical pressure probes (red dots) are used to measure the green water pressures at the center of the deck and breakwater. It can be seen that the green water on deck propagates toward the breakwater and then creates a horizontal impact on the vertical wall of breakwater with a very short rising time.

Fig. 15 shows the time history of the green water pressures at the center of deck and breakwater. The peak pressures are occurring almost simultaneously at the deck and breakwater. It is interesting to note that the pressure at the breakwater is about twice that of the pressure at the deck center, due to the horizontal impact on the breakwater. Unfortunately, the green water height or pressure on deck was not measured during the model tests.

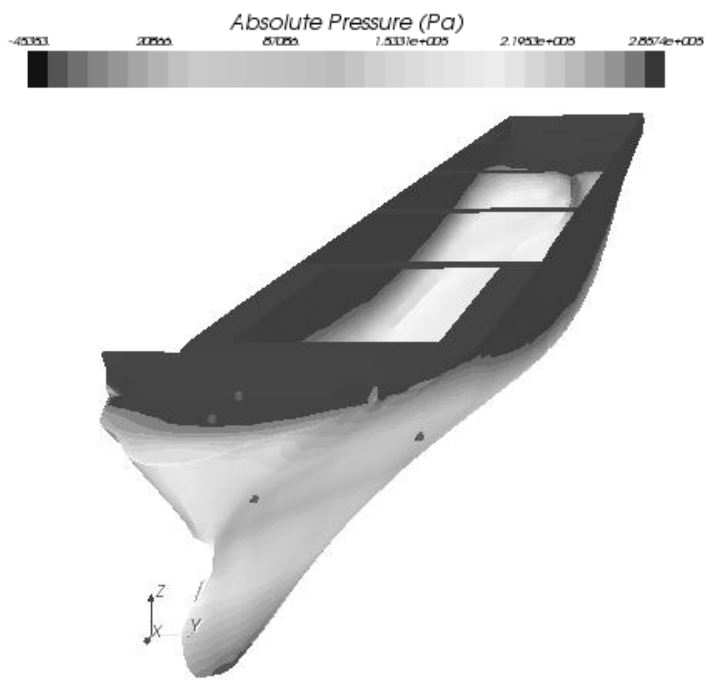

(a) $t=21.0 \mathrm{~s}$

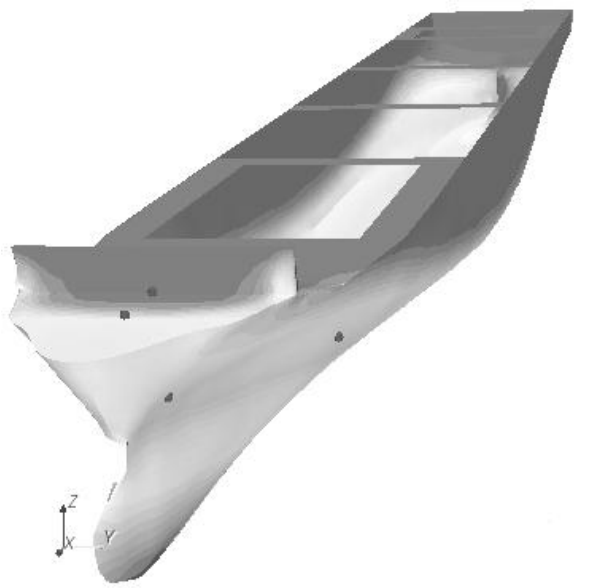

(b) $t=21.4 \mathrm{~s}$

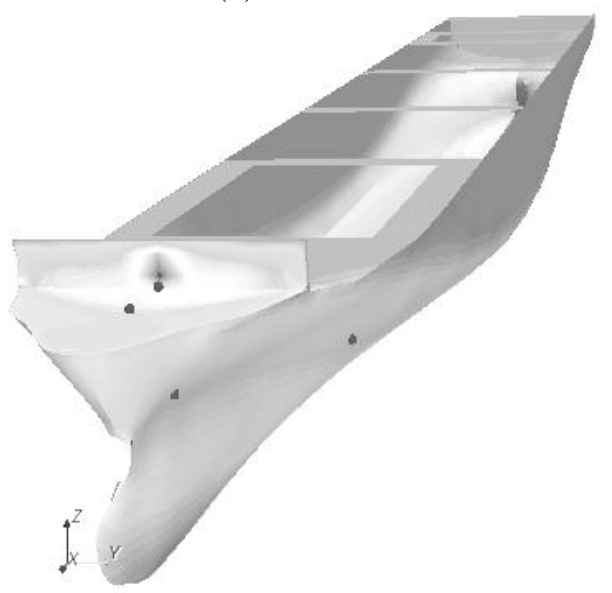

(c) $t=21.8 \mathrm{~s}$

Fig. 14 Instantaneous snapshots of pressure distribution due to the green water on deck and breakwater in the regular waves of Test No. 141. 


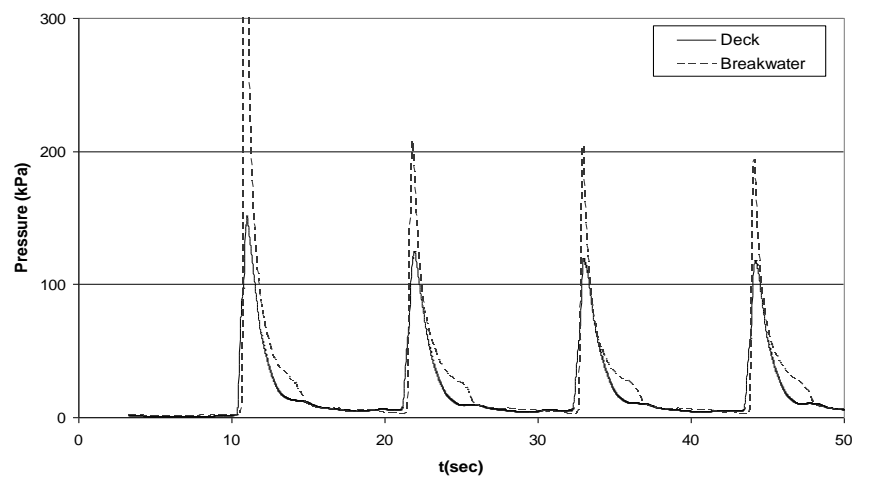

Fig. 15 Green water pressure on deck and breakwater in the regular waves of Test No. 141.

\section{CONCLUSIONS}

This paper presents the validation study of current CFD technology as a seakeeping tool for ship design, focused on the global ship motions and structural loads by fully considering three-dimensional slamming and green water on deck. CFD analyses were carried out for a 6500 TEU container carrier and successfully validated with segmented model test measurements. The summary and conclusions of this study are as follows:

- Fully nonlinear seakeeping analysis using a CFD code was successfully carried out calculating the nonlinear structural loads on a large container carrier in extreme wave conditions

- Excellent agreements on the structural loads were observed between the fully nonlinear CFD analyses and segmented model tests.

- The weakly nonlinear panel method seems to predict the structural loads on the conservative side. The traditional weakly nonlinear analysis is being considered as an efficient and practical method for ship design.

- In this study, CFD analysis procedure and methodology has been developed for fully nonlinear seakeeping analysis. It is demonstrated that the current CFD technology becomes a mature and reliable numerical method for the fully nonlinear seakeeping analysis of large container carriers.

This study is focused on the global ship motion and structural loads rather than local impact loads. The experiments or numerical analysis of the local impact loads such as slamming impact pressures will require further validation study as a future work.

\section{ACKNOWLEDGEMENTS}

The segmented model test has been carried out as part of the joint industry project including major Korean shipyards and Classification societies. The author wishes to gratefully acknowledge Dr. Sa-Young Hong of Maritime and Ocean Engineering Research Institute (MOERI) and other WILS JIP participants for their valuable contributions and technical discussions.

\section{REFERENCES}

American Bureau of Shipping, 2006. Guide for 'SafeHullDyanmic Loading Approach' for Vessels, ABS.

Chen, H.C. and Yu, K., 2009. CFD simulation of wavecurrent-body interactions including greenwater and wet deck slamming, Journal of Computers and Fluids, Vol. 38, No. 5, pp. 970-980.

Hu, C. Kashiwagi, M., 2006. Validation of CIP-based method for strongly nonlinear wave-body interactions," $26^{\text {th }}$ Symposium on Naval Hydrodynamics, Rome, Italy.

Ferziger, J.H. and Peric, M., 2003. Computational Methods for Fluid Dynamics, $3^{\text {rd }}$ ed., Springer, Berlin, Germany.

Kim, S. Shin, Y. and Liu, D., 2006. Advanced dynamic loading approach' for large container carriers based on nonlinear seakeeping analysis, ISOPE conference, San Francisco, USA.

Kim, S. Yu, H.C. and Hong, S.Y., 2010. Segmented model testing and numerical analysis of wave-induced extreme and springing loads on large container carriers, ISOPE Conference, Beijing, China.

Lee, S. Yu, H. Kim, S. Ha, M.-K. Park, G.-I. Choi, J.-W. Kim, M. and Tai, J., 2010. Analysis of hull scale hull girder loads of a container carrier and its simulation using a nonlinear seakeeping program, OMAE conference, Shanghais, China.

The Seakeeping Committee, 2008. Final report and recommendations to the $25^{\text {th }}$ ITTC. Proceedings of the 25th ITTC, Vol. 1, Fukuoka, Japan.

Yang, C. Lu, H. L“ohner, R. Liang, X. and Yang, J., 2007. Numerical Simulation of Highly Nonlinear Wave-Body Interactions with Experimental Validation, Proc Int. Conf Violent Flows, VF-2007, Fukuoka, Japan.

Yu, H.C. Kim, S. Yook, R.-H. Lee, D.-Y. and Jung, H.-C., 2010. The Effect of Icebreaking Bow on the Open Water Performance of a Large Arctic Ore Carrier, ICETECH, Alaska, USA. 